University of Nebraska - Lincoln

DigitalCommons@University of Nebraska - Lincoln

4-1-2002

\title{
Orientation-controlled nonepitaxial L10 CoPt and FePt films
}

H. Zeng

University of Nebraska - Lincoln

M.L. Yan

University of Nebraska - Lincoln

Nathan D. Powers

University of Nebraska-Lincoln, ndp5@byu.edu

David J. Sellmyer

University of Nebraska-Lincoln, dsellmyer@unl.edu

Follow this and additional works at: https://digitalcommons.unl.edu/physicssellmyer

Part of the Physics Commons

Zeng, H.; Yan, M.L.; Powers, Nathan D.; and Sellmyer, David J., "Orientation-controlled nonepitaxial L10 CoPt and FePt films" (2002). David Sellmyer Publications. 47.

https://digitalcommons.unl.edu/physicssellmyer/47

This Article is brought to you for free and open access by the Research Papers in Physics and Astronomy at DigitalCommons@University of Nebraska - Lincoln. It has been accepted for inclusion in David Sellmyer Publications by an authorized administrator of DigitalCommons@University of Nebraska - Lincoln. 


\title{
Orientation-controlled nonepitaxial $\mathrm{L}_{0} \mathrm{CoPt}$ and FePt films
}

\author{
H. Zeng, M. L. Yan, N. Powers, and D. J. Sellmyer ${ }^{a)}$ \\ Center for Materials Research and Analysis and Department of Physics and Astronomy, \\ University of Nebraska, Lincoln, Nebraska 68588
}

(Received 29 October 2001; accepted for publication 4 February 2002)

\begin{abstract}
We report results on highly oriented, face-centered tetragonal ordered CoPt and FePt thin films grown nonepitaxially by directly depositing films on thermally oxidized $\mathrm{Si}$ substrates and subsequent annealing. By controlling the thickness, composition, and annealing conditions, and/or depositing a proper underlayer, nearly perfect (001)-oriented $\mathrm{CoPt}$ and FePt films can be obtained. Magnetic measurements reveal large perpendicular anisotropy for such films. (C) 2002 American Institute of Physics. [DOI: 10.1063/1.1464663]
\end{abstract}

Recently, $\mathrm{L}_{0}$ structured $\mathrm{CoPt}$ and FePt films, ${ }^{1-4} \mathrm{CoPt}$ and $\mathrm{FePt}$ based nanocomposite films ${ }^{5,6}$ and FePt selfassembled nanoparticles ${ }^{7}$ have attracted much attention. These high anisotropy materials show great potential for high-density magnetic recording because of their ability to achieve extremely small grain sizes. ${ }^{7,8}$ Under normal growth conditions, the films often possess (111) preferred or random orientations. ${ }^{1,4}$ For data-storage applications, it is desirable for the magnetic easy axis to orient either in the plane or perpendicular to the plane. ${ }^{9}$ Hence, CoPt and FePt based films with (001) texture have an advantage over randomly or (111)-oriented films. Previously, (001) texture were obtained by epitaxial growth on heated $\mathrm{MgO}(001)$ substrates. ${ }^{10} \mathrm{Pt}$ underlayers also have been used for obtaining (001) textured. ${ }^{11,12}$ Only recently have (001)-oriented FePt: $\mathrm{B}_{2} \mathrm{O}_{3}$ (Refs. 6 and 13) and CoPt/Ag (Ref. 14) nanocomposite films been reported. However, the mechanism of texture formation remains mostly unclear.

In this work, we have prepared nearly perfect (001)textured $\mathrm{CoPt}$ and $\mathrm{FePt}$ films by directly sputtering films on thermally oxidized Si substrates and subsequent annealing. Such films are interesting because the orientation mechanism is totally different from that of epitaxial films. The texture evolution during annealing takes place in three distinctive stages: initial nucleation of nanocrystallites, disorder-order transition, and grain growth and coalescence. Each stage shows different orientation, with different characteristic time scales particular to the material. By controlling these processes, film thicknesses, and compositions, we are able to control the orientation of films.

$\mathrm{CoPt}$ and $\mathrm{FePt}$ films were prepared by sputtering $(\mathrm{Co} / \mathrm{Pt})_{n}$ and $(\mathrm{Fe} / \mathrm{Pt})_{n}$ multilayers, followed by conventional or rapid thermal annealing. The thickness of $\mathrm{Co}(\mathrm{Fe})$ layer was varied while keeping Pt layer-thickness constant, so that the composition could be adjusted. The nominal total thickness was varied from 20 to $900 \AA$. The structural properties were characterized by $\mathrm{x}$-ray diffraction (XRD). The magnetic properties were measured by alternating-gradient-force and superconducting-quantum-interference-device magnetometers.

Figure 1 shows the XRD pattern for a $112 \AA \mathrm{Co}_{50} \mathrm{Pt}_{50}$ sample annealed at $750{ }^{\circ} \mathrm{C}$ for different durations. The annealing time in Fig. 1(a) is $2 \mathrm{~s}$. Only one peak at $48.4^{\circ}$ is clearly visible, which corresponds to neither (200) $\left(47.6^{\circ}\right)$ nor $(002)\left(49.3^{\circ}\right)$ of the face-centered tetragonal (fct) ordered CoPt, but rather the position is in between. The hysteresis loop shows very small coercivity, indicating that the sample structure is disordered face-centered-cubic (fcc) with (100) texture. Upon annealing from 30 to $300 \mathrm{~s}$, the (001) superlattice peak emerges and becomes stronger, while the fcc (200) peak first broadens and eventually splits into two peaks corresponding to (200) and (002) of the ordered fct phase [Figs. 1(b) and 1(c)]. Upon further annealing for $600 \mathrm{~s}$, the (111) peak intensity increases and becomes predominant, indicating the development of (111) texture [Fig. 1(d)].

It is expected that the possible texture evolution process as a function of annealing time takes on three distinctive stages, with different time scales. The first stage, initial nucleation of disordered fcc (100) nanocrystallites, occurs in a few seconds. The (100) texture indicates that the nuclei orientations are not evenly represented, and the (100) orientation prevails over other orientations. This is presumably due to the interaction between the film and the substrate, e.g., strain. The second stage, the disorder-order transition, takes several minutes. Atomic diffusion likely involves only neighboring cells, so that some Co and $\mathrm{Pt}$ atoms interchange their sites without significantly rearranging the whole lattice. The resulting orientation thus has two components, with the su-

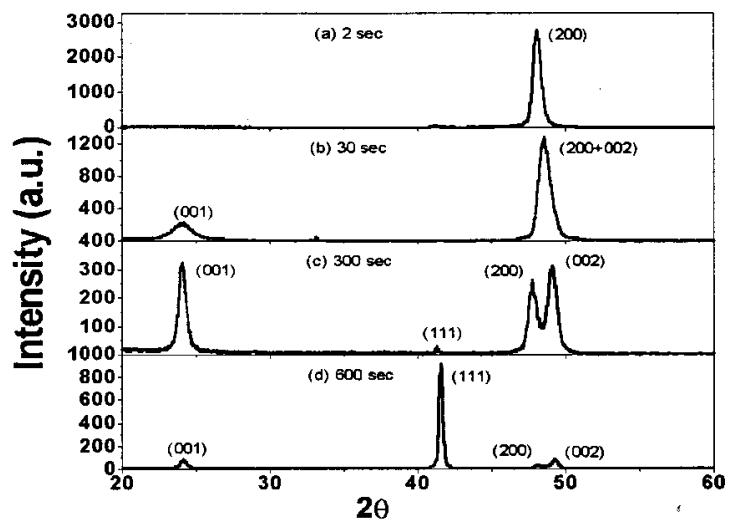

FIG. 1. XRD pattern of $112 \AA \mathrm{Co}_{50} \mathrm{Pt}_{50}$ films annealed at $750^{\circ} \mathrm{C}$ for (a) 2 , (b) 30, (c) 300, and (d) $600 \mathrm{~s}$.

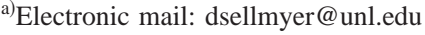




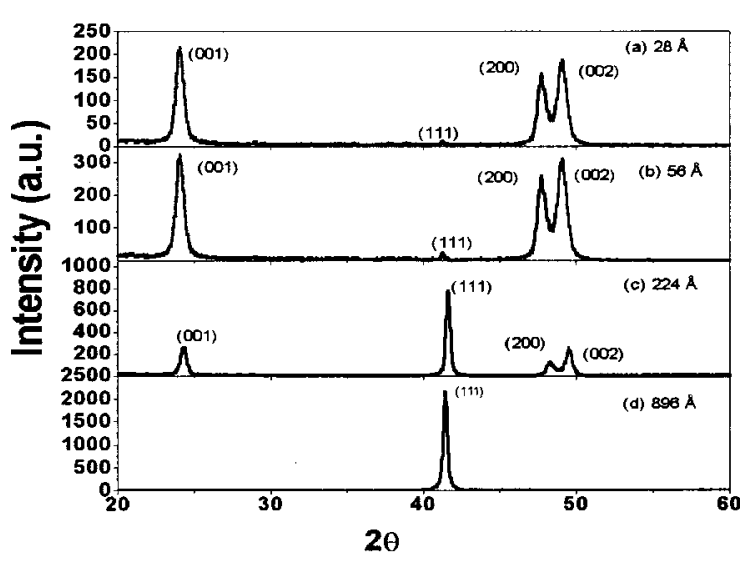

FIG. 2. XRD pattern of $\mathrm{Co}_{50} \mathrm{Pt}_{50}$ films annealed at $750{ }^{\circ} \mathrm{C}$ for $300 \mathrm{~s}$, with varying thicknesses: (a) 28, (b) 56, (c) 224, and (d) $896 \AA$.

perlattice plane parallel $[(001)$ component $]$ and perpendicular $[(100)$ component $]$ to the film plane, both originating from the disordered (100) structure. During this stage, some grain growth and coalescence occurs. ${ }^{15}$ The final stage, prolonged thermal treatment, leads to significant grain growth and coalescence. To minimize the surface energy, the film gradually develops (111) texture, since (111) is the closestpacked plane. The grain sizes estimated from the Scherrer's formula confirm the grain growth process during annealing.

Based on this analysis, suppressing grain growth is essential in promoting (001) and (100) orientations. This can be done by reducing film thicknesses. For thinner films after annealing, the films are no longer continuous but rather constitute separate island-like grains. Once the material between grains is depleted, high diffusion barriers prohibit further grain growth and coalescence. Liou et al. ${ }^{16}$ found that longtime annealed $10 \mathrm{~nm}$ CoPt films form well-separated nanoparticles. The (001) and (100) textures of the nuclei can thus be preserved for thinner films even after long annealing times. Figure 2 shows XRD for $\mathrm{Co}_{50} \mathrm{Pt}_{50}$ films annealed at $750{ }^{\circ} \mathrm{C}$ for $300 \mathrm{~s}$, with the thickness varying from 28 to 896 $\AA$. It can be seen that the thinnest sample shows both (001) and (100) orientations, with only a very weak (111) peak; while the thickest one shows only (111) texture. For intermediate thicknesses, the texture is a mixture of $(001),(100)$, and (111).

We have systematically varied the Co atomic ratio from

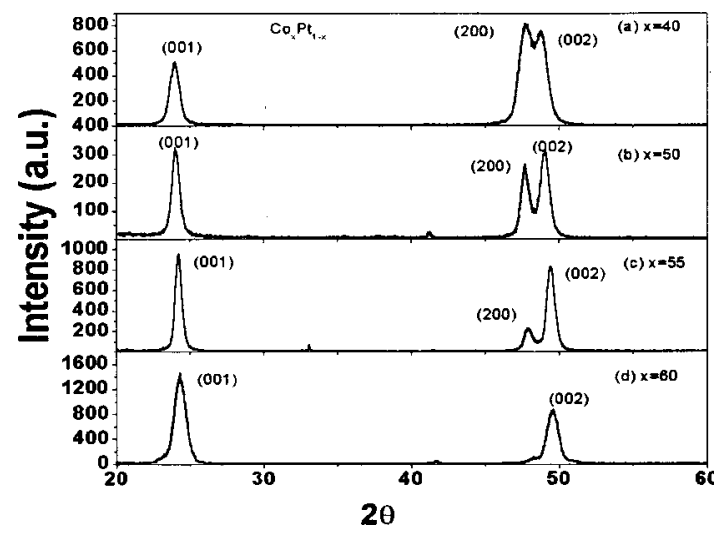

FIG. 3. XRD pattern of $120 \AA \mathrm{Co}_{x} \mathrm{Pt}_{100-x}$ films annealed at $750^{\circ} \mathrm{C}$ for 300

s, with $x=$ (a) 40, (b) 50, (c) 55 , and (d) 60.
Downloaded 16 Nov 2006 to 129.93.16.206. Redistribution subject to AlP license or copyright, see http://apl.aip.

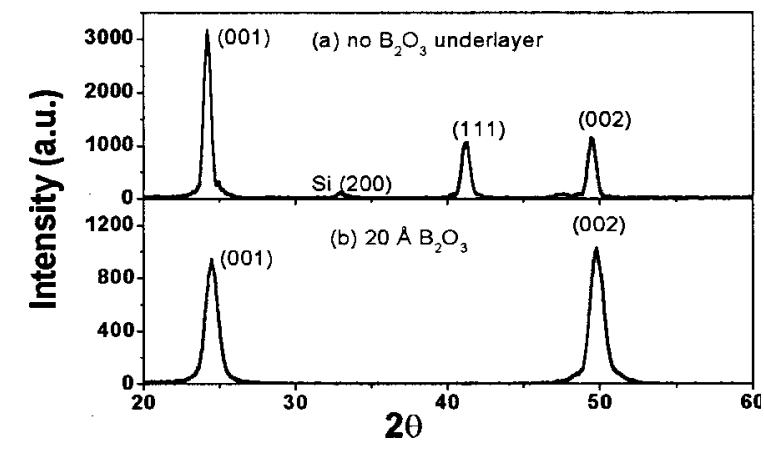

FIG. 4. XRD pattern of $200 \AA \mathrm{Co}_{55} \mathrm{Pt}_{45}$ films annealed at $750^{\circ} \mathrm{C}$ for $600 \mathrm{~s}$. (a) without an underlayer, and (b) with a $20 \AA \mathrm{B}_{2} \mathrm{O}_{3}$ underlayer.

$40 \%$ to $60 \%$, in an attempt to achieve highly oriented (001) CoPt films. It can be seen from Fig. 3 that for films annealed at $750{ }^{\circ} \mathrm{C}$ for $300 \mathrm{~s}$, the $40 \%$ Co film [Fig. 3(a)] shows a strong (200) peak, besides (001) and (002) peaks, while 60\% Co film exhibits predominantly (001) orientation [Fig. 3(d)]. At the same time, with increasing Co composition, all peaks shift slightly toward higher angles. This is to be expected since Co has a smaller atomic radius, which decreases lattice spacing. For fct $\mathrm{CoPt}$ or $\mathrm{FePt}$, the lattice parameter $c$ is slightly smaller than $a$, which may suggest that (001) orientation has lower surface energy than (100) orientation. The reason why Co rich films favor (001) texture to (100) texture is presumably related to the change of surface energy by mutual substitution of $\mathrm{Co}$ and $\mathrm{Pt}$ atoms.

As can be seen next, by depositing a $\mathrm{B}_{2} \mathrm{O}_{3}$ underlayer, and utilizing the interdiffusion between the underlayer and the magnetic film, it is possible to further control the grain size and separations. Figure 4 shows $200 \AA \mathrm{Co}_{55} \mathrm{Pt}_{45}$ films, with and without a $20 \AA \mathrm{B}_{2} \mathrm{O}_{3}$ underlayer annealed at $750^{\circ} \mathrm{C}$ for $600 \mathrm{~s}$. For CoPt films thicker than $60 \AA$ without an underlayer, long-time annealing leads to significant (111) orientation. However, with only a $20 \AA \mathrm{B}_{2} \mathrm{O}_{3}$ underlayer, the texture after long-time annealing is still (001), and the grain size is significantly smaller than without the underlayer. This suggests that during annealing, $\mathrm{B}_{2} \mathrm{O}_{3}$ diffuses into the grain boundaries and builds up diffusion barriers, which suppresses the grain growth and coalescence. Grain boundary segregation of nonmagnetic materials also helps to reduce the intergrain exchange coupling. ${ }^{8}$

So far, we have seen that obtaining highly oriented (001) texture requires a balance of the thermal treatment time to

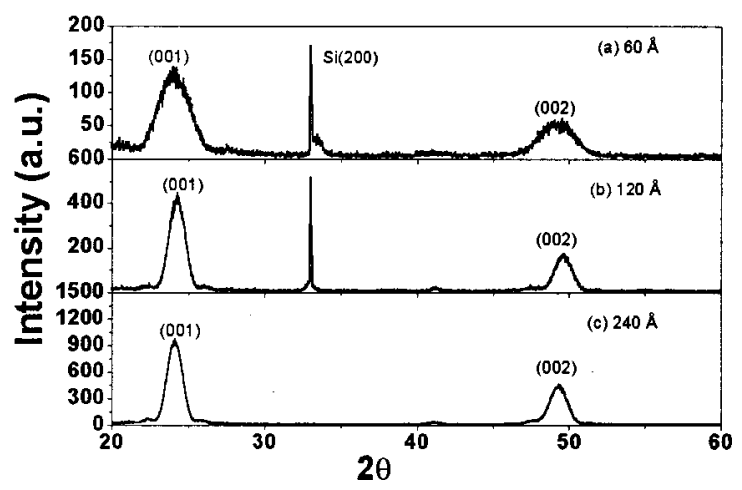

FIG. 5. XRD pattern of $\mathrm{Fe}_{55} \mathrm{Pt}_{45}$ films annealed at $550{ }^{\circ} \mathrm{C}$ for $2 \mathrm{~s}$, with

varying thickness: (a) 60 , (b) 120 , and (c) $240 \AA$.
o AIP license or copyright, see http://apl.aip.org/apl/copyright.jsp 


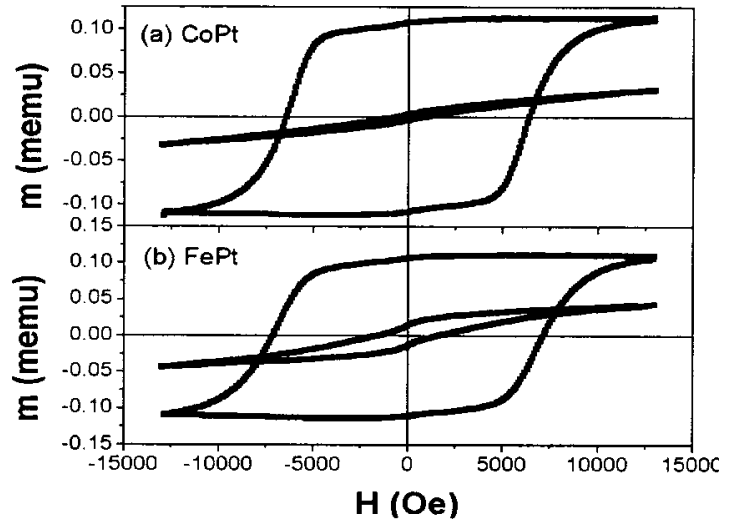

FIG. 6. Typical hysteresis loops for (a) $100 \AA \mathrm{CoPt}$ annealed at $750^{\circ} \mathrm{C}$ for $300 \mathrm{~s}$ and (b) $100 \AA \mathrm{FePt}$ annealed at $550^{\circ} \mathrm{C}$ for $5 \mathrm{~s}$.

ensure sufficient ordering while at the same time minimizing the grain growth. Thinner films with slightly Co rich compositions are also essential. A suitable underlayer can help to achieve nearly perfect (001) texture.

FePt films show similar behavior. However, the ordering takes place at significantly lower annealing temperature and shorter time, suggesting a large difference in diffusion efficiency from CoPt. Figure 5 shows XRD data for $\mathrm{Fe}_{55} \mathrm{Pt}_{45}$ films annealed at $550{ }^{\circ} \mathrm{C}$ for $2 \mathrm{~s}$, with nominal thicknesses from 60 to $240 \AA$. All the samples show only (001) and (002) superlattice peaks, aside from the (200) peak of Si. Unlike $\mathrm{CoPt}$, the ordering occurs within a few seconds of annealing, so that there is neither a significant disordered fcc phase nor significant grain growth and coalescence leading to (111) texture during this stage. These characteristics ensure that nearly perfect (001) texture can be achieved for FePt films at moderate annealing temperatures and short times, with very small grain sizes, as opposed to CoPt films. The grain size estimated from Scherrer's formula for the $240 \AA$ AePt sample is only $6.7 \mathrm{~nm}$.

Typical hysteresis loops for a $100 \AA \mathrm{CoPt}$ film annealed at $750{ }^{\circ} \mathrm{C}$ for $300 \mathrm{~s}$. and $\mathrm{FePt}$ film at $550^{\circ} \mathrm{C}$ for $5 \mathrm{~s}$, in directions both perpendicular and parallel to the film, are shown in Fig. 6. It is seen that for both films, the easy axis is in the perpendicular direction, which is consistent with XRD results. The perpendicular loops show large coercivity $(>7 \mathrm{kOe})$ and high remanence ratio.

In summary, we have produced nearly perfect (001) oriented CoPt and FePt films. These films are grown nonepitaxially on thermally oxidized $\mathrm{Si}$ substrates. In the case of FePt, optimum magnetic properties can be achieved at moderate annealing temperature and short annealing time, with very small grain sizes. The nanostructures can be further controlled by the proper underlayer for better texture and smaller grain sizes and intergrain exchange coupling. The processes and substrates used are much more compatible with practical applications than those used to grow epitaxial films.

Research supported by NRI, NSIC, IBM, and CMRA.

${ }^{1}$ K. R. Coffey, M. A. Parker, and J. K. Howard, IEEE Trans. Magn. 31, 2737 (1995).

${ }^{2}$ C. P. Luo and D. J. Sellmyer, IEEE Trans. Magn. 31, 2764 (1995).

${ }^{3}$ C. P. Luo, Z. S. Shan, and D. J. Sellmyer, J. Appl. Phys. 79, 4899 (1996).

${ }^{4}$ R. F. C. Farrow, D. Weller, R. F. Marks, M. F. Toney, A. Cebollada, and G. R. Harp, J. Appl. Phys. 79, 5967 (1996).

${ }^{5}$ M. Yu, Y. Liu, and D. J. Sellmyer, Appl. Phys. Lett. 75, 3992 (1999).

${ }^{6}$ C. P. Luo, S. H. Liou, L. Gao, Y. Liu, and D. J. Sellmyer, Appl. Phys. Lett. 77, 2225 (2000).

${ }^{7}$ S. Sun, C. B. Murray, D. Weller, L. Folks, and A. Moser, Science 287, 1989 (2000)

${ }^{8}$ D. J. Sellmyer, C. P. Luo, and H. Zeng, in Magnetic Storage Systems Beyond 2000, edited by G. C. Hadjipanayis (Kluwer, Dordrecht, 2002), p. 163.

${ }^{9}$ C. D. Mee, Magnetic Recording Technology (McGraw-Hill, New York, 1996).

${ }^{10}$ B. M. Lairson, M. R. Visokay, R. Sinclair, and B. M. Clemens, Appl. Phys. Lett. 62, 639 (1993).

${ }^{11}$ M. R. Visokay and R. Sinclair, Appl. Phys. Lett. 66, 1692 (1995).

${ }^{12}$ M. Watanabe and M. Homma, Jpn. J. Appl. Phys., Part 2 35, L1264 (1996).

${ }^{13}$ C. P. Luo, Ph.D Dissertation, University of Nebraska, 2001.

${ }^{14}$ V. Karanasos, I. Panagiotopoulos, D. Niarchos, H. Okumura, and G. C. Hadjipanayis, Appl. Phys. Lett. 79, 1255 (2001).

${ }^{15}$ L. Eckertová, Physics of Thin Films (Plenum, New York, 1986).

${ }^{16}$ S. Liou, Y. Liu, S. S. Malhotra, M. Yu, and D. J. Sellmyer, J. Appl. Phys. 79, 5060 (1996). 